\title{
HIGH-FREQUENCY ELECTRIC CURRENT FOR DRYING OF WOOD - HISTORICAL PERSPECTIVES
}

\section{Helmuth Resch}

\author{
In memoriam of Dr. Walter G. KAUMAN
}

\begin{abstract}
Among the many interesting topics in the field of Wood Science and Technology is a fascinating story about research and development on drying wood products with high-frequency electric current. Historically, it can be traced back over decades.

Heat transfer to and evaporation of moisture from wood may be accomplished with high frequency current depending on its dielectric properties. Because wood is generally heterogeneous, these properties vary not only with the frequency of the current and the field orientation, but also with the moisture content, temperature, and density of wood. Considering these parameters and the specific heat of the material, estimates of power absorption can be made.

In an attempt to develop this technology, research covered many products from paper and veneer to lumber and heavy timbers. Much emphasis, however, has been placed on wood species and/or products with larger dimensions that are difficult or impossible to dry when using conventional drying methods. The advantages of employing dielectric heating were found to be rapid and fairly uniform heat transfer often to solidly stacked timbers, very high drying rates, and avoidance of various drying defects including any significant case-hardening and oxidative discoloration of the wood.

During the last two decades, the development focused mainly on drying lumber in vacuum kilns using dielectric heating, often termed high-frequency/vacuum drying. It has been justified economically on the basis of increased throughput and higher quality. Existing industrial installations provide a positive picture for higher value products. The economics should improve with advances in available equipment, better basic understanding and more practical experience with industrial units now operating. Also, the combination of high-frequency/vacuum drying with other systems, such as moisture leveling after primary drying or pre-heating prior to the high-frequency/vacuum step, hold promise for further technical improvement.
\end{abstract}

Keywords: Wood drying. Hf-current

\section{Dielectric heating of wood}

For industrial processing with high-frequency (Hf) electric current, two different frequency ranges may be distinguished: radio frequencies (Rf) below $100 \mathrm{MHz}$, using open wire circuits, and microwaves at frequencies above $500 \mathrm{MHz}$, using waves guides to transfer power to material contained in them. The term dielectric heating refers to both and the effects on materials, such as polarization and conduction, are similar. For industrial processing, international agreement designated the frequencies in Table 1 that are related to wavelengths in free space. However, other frequencies have been used for equipment with proper shielding. 
Table 1. Frequency bands for industry

\begin{tabular}{|l|c|c|}
\hline & Frequency & Wave length \\
\hline & $\mathrm{MHz}$ & $\mathrm{m}$ \\
\hline Radio frequencies & 13.56 & 22.11 \\
\hline & 27.12 & 11.05 \\
\hline & 40.68 & 7.37 \\
\hline Microwaves & 915 & 0.328 \\
\hline & 2450 & 0.122 \\
\hline & 5800 & 0.052 \\
\hline
\end{tabular}

Heating is influenced by the material structure. A field of high frequency electromagnetic waves is able to polarize charges in insulating materials. This polarization, however, cannot follow the extremely rapid reversals of the dielectric field. The polarization vector $P$ lags the applied electric field so that the resulting current $\delta P / \delta t$ has a component in phase in this field, thus, dissipating power within the insulating material. Orientation polarization is caused by permanent dipoles contained in polar dielectrics that reorient under the influence of a changing electric field. Induced polarization stems either from the displacement of electrons around the nuclei or from the relative displacement of atomic nuclei themselves. Further, interfacial polarization arises from space charges built up in interfaces between heterogeneous components.

The average dipole moment of a displaced dipole is the product of the charge $q$ and the charge separation $x_{i:} \mu=q x_{\mathrm{i}}$. Together all dipole moments within a volume $\Delta v$ containing $N$ dipoles amount to the charge density of the polarization field $P$ :

$$
P=\sum_{i=1}^{N} \frac{q x_{i}}{\delta_{v}}
$$

The electric charge density vector D may express the total charge of the interface between the dielectric and the surrounding medium. The difference between the two vectors accounts for the remaining free charges of the system. Thus,

$$
D=\varepsilon_{0} E+P=\varepsilon_{0} \varepsilon^{\prime} E
$$

Where $\varepsilon_{0}$ is the dielectric constant of free space, $E$ the externally applied electric field, and $\varepsilon^{\prime}$ the relative dielectric constant, often just termed the dielectric constant. The previous equation yields $P=$ $\left(\varepsilon^{\prime}-1\right) \varepsilon_{0} E$ and the ratio of the bound to the free charges is referred to as electric susceptibility

$$
X=P / \varepsilon_{0} E=\left(\varepsilon^{\prime}-1\right)
$$

Because the polarization field $P$ contains individual dipole moments $P=\mu N^{\prime}$ and the local field $E$ ' applies to the individual dipole, the dipole moment $\mu$ is a simple function of the field:

$$
\mu=\alpha_{t} E^{\prime}
$$

Where $\alpha_{t,}$ the polarisability of the material, embodies the different components of polarization, indicated by the subscripts for electronic, atomic, dipolar, and interfacial polarization:

$$
\left.\alpha_{\mathrm{t}}=\alpha_{\mathrm{e}}+\alpha_{\mathrm{a}}+\alpha_{\mathrm{d}}+\alpha_{M W} \text {, thus, ( } \varepsilon^{\prime}-1\right) \varepsilon_{0} E=\alpha_{t} N^{\prime} E^{\prime}
$$




\section{Dielectric Properties}

In heating wood by high frequency current, losses due to electronic and atomic polarization can be neglected. The complex dielectric constant $\varepsilon^{*}$ that becomes effective for high frequency heating includes the imaginary part $\mathcal{\varepsilon}_{\text {eff }}$ as loss factor:

$$
\varepsilon^{*}=\varepsilon^{\prime}-j \varepsilon^{\prime \prime}{ }_{e f f}
$$

The effective loss tangent, the ratio of the effective loss factor to the dielectric constant, is a material property reflecting the effects of applied electric field vectors and direct current conductivity. It stands for the high frequency electric energy dissipated in the material and subsequently transformed into thermal energy:

$$
\tan \delta_{e f f}=\varepsilon^{\prime \prime}{ }_{\text {eff }} / \varepsilon^{\prime}
$$

The dissipation of energy in the frequency range from $10 \mathrm{MHz}$ to $3 \mathrm{GHz}$ is influenced mainly by two different mechanisms: dipolar and interfacial relaxation. If significant amounts of conductive phases are present, as may be the case with water-saturated wood, the conductivity $\sigma$ and the angular frequency $\omega$ have to be considered also. Interfacial polarization can then be expressed:

$$
\varepsilon_{d c}{ }^{\prime \prime}=\sigma / \omega \varepsilon_{0}
$$

Losses due to a conductive phase in a heterogeneous dielectric combine with dipolar losses to amount to the effective loss factor $\varepsilon^{\prime \prime}$ eff.

For proper equipment design and efficient processing of materials, their dielectric properties must be known. However, both components of the complex dielectric constant or permitivity $\varepsilon^{*}$, namely $\varepsilon^{\prime}$ and $\varepsilon_{e f f}$, are frequency and temperature dependent. Von Hippel (1954) researched the dielectric properties of a wide range of inorganic and organic materials in the frequency and temperature ranges from 100 to $10^{10} \mathrm{~Hz}$ and -12 to $200^{\circ} \mathrm{C}$ respectively. Tinga and Nelson (1973) followed with a focus on biological substances. Hearmon and Burcham (1954) James and Hamill (1965) as well as James (1975) concentrated specifically on wood and its products and finally Torgovnikov (1993) brought together a large body of knowledge about dielectric properties of wood and wood-based materials.

Obviously, the presence of water, which is polar and exhibits strong dipole moments, increases in any material the effective loss factor and makes it a good candidate for processing with high frequency energy. Because application of dielectric heat causes changes in moisture contents, the variation of $\varepsilon^{*}$ and in particular $\varepsilon$ " eff with moisture content is important. Bound water is tightly held and less rotationally free than the free water present in various cavities. Thus, the latter makes higher dielectric losses possible.

For practical purposes, the influences of the anisotropy of wood, the fiber orientation in respect to the electric field, must be considered also. The optimum field orientation in an applicator may be deduced from the $\varepsilon^{\prime \prime}{ }_{\text {eff }}$ versus moisture content curves as losses are higher for the field orientation parallel to the grain, which is characteristic of wood and paper products (James and Hamill, 1965). Each material possesses different curve forms for different frequency ranges. Further, the slope of the $\varepsilon^{\prime}{ }_{\text {eff }}$ versus moisture content curve is critical to industrial applications where moisture leveling of a material, especially in sheet form, is the main objective (Resch, 1968). Above a critical value of moisture content, wetter parts of a material absorb more power and tend to level off an initially uneven moisture distribution. Below the critical value, moisture leveling becomes less and less effective as $\varepsilon_{\text {"ff }}$ becomes almost independent of moisture content when different parts of the material absorb similar amounts of energy from the high frequency field. Finally, variations in density always exist between and within species and the temperature must be controlled in most industrial processes. To consider such complex interactions, 
look up tables, exemplified by those of Torgovnikov (1993), may be constructed and used for specific calculations.

\section{Volumetric Heating}

The average of power absorbed within a dielectric material can be stated assuming the electric field $E$ established in the material as constant:

$$
P_{\text {avg }}=\omega \varepsilon_{0} \varepsilon^{\prime \prime} E^{2} v
$$

Substituting $\varepsilon_{0}=8.8^{*} 10^{-12} \mathrm{~F} / \mathrm{m}$ and $w=2 \pi f$, renders $P_{\text {avg }}=0.556 * 10^{-10} f \varepsilon^{\prime \prime}{ }_{\text {eff }} E^{2} v$

$P_{\text {avg }}$ is expressed in $\mathrm{W}$ when $E$ is in $\mathrm{V} / \mathrm{m}, f$ in $\mathrm{Hz}, v$ in $\mathrm{m}^{3}$ while electron spin losses are ignored.

Considering the current flow through a lossy capacitor that is connected across a sinusoidal voltage

$$
i=i_{R}+i_{C}=V / R^{\prime}+C d V / d t
$$

The capacitance for a cross sectional area of the capacitor plates $A_{c}$ and their separation $d$ is

$$
C=\varepsilon_{0} \varepsilon^{\prime} A_{c} / d
$$

Thus, the product of $f$ and $\varepsilon^{\prime \prime}{ }_{\text {off }}$ strongly influences the calculation of the power density within a dielectric material explaining why greater power densities can be obtained with microwaves:

Power / unit volume, $p=\omega \varepsilon_{0} \varepsilon^{\prime \prime} E^{2}$.

The enthalpy of a system at a given pressure, volume, and internal energy $U$ is given by $H=U+p v$ and may be shown in differential form:

$$
U=d Q_{h}-p d v
$$

The specific heat can be calculated by differentiating with respect to temperature and constant volume

$$
c=(\delta U / \delta T) v=\delta Q_{h} / \delta T
$$

Taking the specific heat of water as $4.19 \mathrm{~kJ} / \mathrm{kgK}$, the influence of moisture content of wood can be estimated for the major European species to fall between 1.35 and $2.83 \mathrm{~kJ} / \mathrm{kgK}$ (Dunlap 1912, Kollmann 1951).

\section{Early developments}

W.R. Whitney of the General Electric Co. in the USA, apparently prior to 1928, conceived the idea to dry wood and similar materials in a high frequency (Hf) electric field and the agent, John Gray, applied for a British patent in March of the following year (Tiemann 1944). In 1934, Abramenko published on experiments, carried out during the previous years, to dry wood by this method. Also Matsumoto (1934) filed for a Japanese patent. Stephen and Holmquest $\left(1936^{\mathrm{a}}, 1936 \mathrm{~b}\right)$ followed up with drying studies on lumber and Voigt et al (1940) providing a technological overview. The first patent for drying of lumber in vacuum while heating it by high frequency current (HfV) was granted to Luth and Krupnick in 1945. Hf-heating for seasoning of wood was also suggested by Miller (1948) in Canada, and studied by Murata and Iso (1949) in Japan. Its economic aspects were considered by Birjukow in Russia in 1950, at a time when the cost of electricity seemed set to decrease in the future. 
In the 1960s, research and development on the Hf-drying accelerated in a number of countries and results were reported by a fair number of researchers (Jagdfeld 1963, Gillwald 1964, Gefahrt 1966 and 1967, Dean 1963, Miller 1966, Czepek and Sporkmann 1968, Resch 1966, 1967, 1968, Resch et al.1970, Pound 1973).

\section{Continuous radio-frequency dryer}

At that time, probably the best known tunnel dryer using Rf-current for heating short pieces of European beech had been designed by Brown, Boveri \& CIE in 1963 (Czepek, Sporkmann 1968). Located in Southern Germany, it dried mainly beech wood $150 \mathrm{~mm}$ in length in the production of forms for shoe design. A metal link-chain belt, serving as one electrode, carried the material through an $11 \mathrm{~m}$ long tunnel. The hot electrodes suspended above could be adjusted in height as to provide an optimum electric field for the changing dielectric properties of the drying wood. The generator worked at $13.56 \mathrm{MHz}$ with power adjustable between 2 and $25 \mathrm{~kW}$. Its tubes were air cooled through a blower and the warm air ducted into the tunnel to prevent condensation on tunnel walls and transfer some heat to the wood as well. Vents provided for the exhaust of moist air. The wood, that had first been air-dried to just below the fiber saturation point, could be dried with hardly any defects to fairly uniform final moisture content of about 9 percent. In fact, most of the pieces contained slightly lower moisture content in the core than in the shell, the opposite to the moisture gradient normally encountered after convection drying. This reflected the different drying mechanism explained later.

\section{Radio-frequency/Vacuum drying}

RfV drying technology constitutes a combination of two special methods: heating by high frequency current and drying in vacuum where the boiling point of water is decreased with decreasing pressure. Consequently, the movement of water through wood increases leading to shorter drying times than can be achieved at atmospheric pressure. The intensity of the heating depends directly on the moisture content of the wood and the electric field, while the moisture movement depends on the permeability of the wood and the internal pressure gradient. At radio frequencies, the penetration depth influences the dimensions of the electric field that is of the order of meters, thus, making possible the heating of entire stacks of lumber.

The first industrial RfV dryers were built by the Russian Academy of Science in Moscow apparently in the 1960s. Some models had dimensions of $8 \mathrm{~m}$ lengths, $3 \mathrm{~m}$ heights and $3 \mathrm{~m}$ widths that accommodated about $10 \mathrm{~m}^{3}$ of lumber. The Rf-generator, located on top of the vacuum chamber, working at a frequency of $13.56 \mathrm{MHz}$ and using about $44 \mathrm{~kW}$, could produce a maximum of $10 \mathrm{kV}$ Hf-current between the electrodes. Internal water vapor condensation was possible on cooled pipes. Its main use was for drying furniture stock from Russian hardwood species (Djakonov and Gorjaev, 1981).

In the USA, a small HfV dryer was built and patented by Koppelman (1976). In its cylinder, lumber was dried between two electrodes with water vapor being condensed originally on the cooled cylinder walls, later in an outside condenser. The advantages of high product quality and short drying times were proven experimentally by Harris et al. (1984) and Trofatter et al. (1986).

\section{Microwave drying}

In the 1940s, the advent of the magnetron gave a start to industrial microwave heating for cooking and drying. The preferred frequencies were $2450 \mathrm{MHz}$ and $915 \mathrm{MHz}$. In contrast to Rf-heating, microwaves may provide for greater heating intensity, however, have limits for wood products when they cannot penetrate deeply enough or provide uniform heating. In general, power penetration depth decreases with shorter wavelength, that is, increasing frequencies. Penetration depths at radio frequencies are of 
the order of meters and, unless the loss factor is extremely high, through heating may be assured. In the microwave region, on the other hand, the penetration depths become very small, especially when a material is very wet. Non-uniform temperature distribution is the result when the size of the material to be heated is greater than the penetration depth of the radiation.

It seemed logical to apply the new technology of microwave heating and drying in the field of forest products (Egner and Jagfeld 1964; Resch 1968) especially as continuous processes for thinner materials such as thin lumber (Resch 1966; Mc Alister and Resch 1971), pencil slats (Resch 1967) and veneer (Resch et al. 1970).

The first production-sized, continuous microwave-hot air dryer was built by the Cryodry Corp. and set up at the Yakima plant of the Boise-Cascade Corp. Using 50kW microwave power of $915 \mathrm{MHz}$ frequency, it was developed to level the moisture content in softwood veneer that had remained too wet after primary drying. Rollers conveyed veneer sheets to pass through slotted wave-guides that were arranged in meanders. Hot air jets positioned between the wave-guides and rollers impinged on the veneers and carried off evaporating moisture. Drying selectivity obtained was due to a greater microwave absorption in wetter areas, often well-defined wet pockets and streaks. Microwave re-drying prevented over-drying and kept the veneer at equal or better quality than re-drying with hot air (Resch et al. 1970).

\section{Radio-frequency batch dryers}

As an alternative to a continuous microwave dryer for leveling moisture content in re-dry veneer, Speco Inc., in 1982, manufactured an Rf-batch dryer. Reportedly, it was able to bring the moisture contents of $1.22 \times 2.44 \mathrm{~m}$ veneer sheets in a $0.76 \mathrm{~m}$ high stack into the desired range within 14 minutes. The $300 \mathrm{~kW}$ generator worked at $13.56 \mathrm{Mz}$ and the temperature of the chamber was maintained by hot air at $150^{\circ} \mathrm{C}$. Of course, there were by far fewer moving parts in such a dryer as conveyance to and from the dryer was by forklifts and loading was automatic.

\section{R\&D and industrial installations during the last decades}

\section{Radio-frequency/vacuum dryers}

In the 1990s, interest was renewed in dielectric heating of wood as part of the drying technology. Using Rf-heating, the combination with vacuum drying emerged as the best option for most applications in the solid wood products industry.

In the USA, Dimension Drying Inc. built an RfV dryer specifically designed to dry red oak furniture parts at Norton Smith Lumber Co. (Smith et al. 1996). It employed an Hf-generator working at 2 to $4 \mathrm{MHz}$ using Siemens tubes with life expectancies between 2000 and 4000 hours. The chamber, having a capacity of roughly $20 \mathrm{~m}^{3}$, could be evacuated to a pressure level as low as $2.3 \mathrm{kPa}$. At one time, four such dryers were reported operating commercially in the State of New York.

In Canada, the success in drying hardwoods caused interest in the softwood lumber industry. In a new RfV chamber with $23 \mathrm{~m}^{3}$ capacity, softwood lumber of various Canadian species was dried at a frequency of $3 \mathrm{MHz}$ and a maximum power of 260kW (Avramidis and Zwick 1992; Avramidis et. al., 1994, 1996, 1997). Avramidis presented an overview of this technology in 1999 at a workshop in Scotland.

The RfV technology succeeded in drying large lumber sizes that are commonly not dried in conventional kilns because hot-air dryers would need excessive times and cause unacceptable defects. The research was carried out on wood of the major Canadian West Coast softwoods with dimensions ranging in thickness from 36 to $152 \mathrm{~mm}$ and in width from 101 to $190 \mathrm{~mm}$. Proper schedules with acceptable time frames eliminated lumber staining and internal stresses and greatly reduced surface checking 
(Avramidis and Zwick 1996). Based on this research, HeatWave Technologies Inc. developed a number of models of commercial RfV dry kilns.

One such RfV-kiln, or rather two units linked together working at $13.56 \mathrm{MHz}$ and a maximum of 40kW, have been installed by Forest Grove Lumber Co. in Oregon. This wholesaler markets RfV-dried, large Douglas fir timbers under the trade name Tru-Dry asserting high quality, structural integrity, and good appearance. Each unit is $12.2 \mathrm{~m}$ long and $1.22 \mathrm{~m}$ wide to accommodate timbers with cross sections ranging from $152 \times 152 \mathrm{~mm}$ to $254 \times 254 \mathrm{~mm}$. To prevent or reduce warp, a top weight of about $113 \mathrm{t}$ is placed on them during drying. Drying time ranges from about 4 to 6 days depending on timber size.

The construction of the apparently largest HeatWave unit with $75 \mathrm{~m}^{3}$ capacity and $300 \mathrm{~kW}$ radio frequency output was announced in 2001 for the main purpose of re-drying Western hemlock and white fir lumber that had remained too wet during primary hot air convection drying (Elustondo and Avramidis, 2001). The scheme is mentioned below in context of combination processes.

In Japan as well, a number of companies constructed Hf-lumber dryers with $13.56 \mathrm{MHz}$ frequency generators and capacities ranging from 5 to $40 \mathrm{~m}^{3}$ (Yasujima 2001, Mokushin 2001, Fuji Electronic Ind. 2003). While Yasujima decided on the RfV approach using two cylinders as drying chamber and water vapor condenser respectively, others opted for so-called hybrid kilns combining Rf-heating with hot air convection drying at atmospheric pressure.

In Austria, a commercial RfV-drying chamber, manufactured in Russia on the basis of the design by the Academy of Science in Moscow, had been obtained to investigate the feasibility of this technology for drying major European hard- and softwood species (Resch and Gautsch 2000). This plant with a maximum capacity of $10 \mathrm{~m}^{3}$ and a rather old generator providing a maximum high frequency voltage of $10 \mathrm{~kW}$ at $13,57 \mathrm{MHz}$ was fitted with load cells and condensation traps to determine the rate of drying and with fiber optics to measure the temperature of the wood. Results were rather promising for beech, birch, and spruce lumber of common sizes that could be dried in 2 to 4 days while oak proved to be much more refractory. In addition, a small, $1.5 \mathrm{~m}$ long, highly instrumented laboratory RfV-dryer was constructed allowing the continuous measurement of weight, temperature, and pressure in wood and chamber (Resch and Hansmann 2002). Among the tests with this equipment, $75 \mathrm{~mm}$ thick boards of Eucalyptus globulus could be dried rapidly, in about 290 hours, from about $42 \%$ to $11 \%$ moisture content without the development of collapse and significant checks. Based on the measurement of internal pressure during drying and residual strain in the wood, it was concluded that the drying mechanism is a combination of pressure flow and diffusion of moisture to the surface. It is that pressure flow which accounts for the high rate of drying as well as the low stress development.

In China, research by Li et al. (2005) proved the RfV concept (using 6.78Mhz) quite applicable for drying plantation poplars containing initially very high amounts of moisture.

\section{Microwaves}

To overcome problems of field distribution and power intensity when designing a continuous microwave dryer, multimode applicators have been suggested to advance that technology further toward industrial application (Antti 1992, 1999; Hansson and Antti 2003; Leiker et al. 2004b and 2005). Further improvement of this concept is the additional application of a vacuum to reach even higher drying rates and improving the quality of the dried material (Leiker, Adamska 2004). Two magnetrons working at $2450 \mathrm{MHz}$ and up to $3 \mathrm{~kW}$ each were able to dry $50 \mathrm{~mm}$ thick beech samples at a rate of about $7 \% / \mathrm{min}$ without material damage (Leiker et al.2005). Of course, such high drying rates hold promise toward the goal of a continuously working lumber dryer. 


\section{Combination processes}

Hf drying units may be used not only where quality improvement is possible, but also where conventional methods become very slow or inefficient. This is the case when drying wood toward the end of the «falling rate period» prior to reaching the final moisture content. Thus, a combination of drying systems can increase total throughput appreciably thereby reducing space and inventory requirements.

Classic examples were the re-drying of veneer after a primary drying process either using microwaves or Rf-current coupled with hot air convection. Conventionally, but rapidly dried material often has a spread in final moisture contents that is too large and not acceptable for further processing. Thus, redrying is required of the material that had remained too wet. Here, dielectric heating offers important advantages: Dielectric current delivers more heat to wet than to dry areas. This levels the moisture content and helps retain product quality as has been demonstrated with a continuous microwave dryer (Resch et al.1970) and stationary Rf-dryers (Wilson 1989).

A further improvement of this concept is the addition of a vacuum. An RfV- dryer can also be used for re-drying of softwood lumber (Elustondo and Avramidis 2002). HeatWave Technologies installed such a unit at Hampton Lumber Co. in the State of Washington. There, hot air convection kilns dry Western hemlock and White fir structural lumber to a target of average moisture content of $17 \%$. This primary drying step leaves a fairly large portion of boards above $18 \%$ as too wet. That portion has to be sorted out by means of a moisture probe and then taken to the RfV-re-dryer. With generators producing $300 \mathrm{~kW}$, the moisture content of the lumber is being leveled and reduced to a final moisture target of about 16 to $18 \%$. The advantage of this "dry, sort and dry" approach lies not only in the shorter drying time through the kilns, but also mainly in a reduction of degrade and shrinkage of lumber that otherwise would have been over-dried. That reduction in shrinkage allows for a somewhat smaller target size in sawing and therefore for a reduction in raw material used.

In Asia, studies focused on other alternatives and wood species. Because in conventional drying, especially of refractory woods, the dangers of collapse and checking exist, long drying times are normally mandated. To reduce steep moisture gradients that lead to large drying stresses, intermittent Hf-radiation might be useful. Instead of a steaming treatment, conditioning of Eucalyptus board sections was possible with microwaves at $2450 \mathrm{MHz}$. It proved successful in obtaining stress relaxation to a large extent (Wang 2005).

The combination of microwave radiation and convective hot air heat transfer to Korean red pine timber with a 150 by $150 \mathrm{~mm}$ cross section proved only partially successful (Lee 2005). This approach of rapid drying reduced the amount of defects compared to those normally occurring with hot air drying, but the formation of checks led to the conclusion that further research was needed.

Other combination processes seem possible such as pre-heating by conventional means, such as presteaming of green lumber with all the moisture in it, followed by HfV drying. The steaming would provide the relatively large amount of energy needed in first heating up, leaving only the energy needed for evaporation to the Hf source. In other words, there are still exciting opportunities for research and industrial development in this field.

\section{Toward fuller understanding}

The experience gained from research and development in Hf-drying answered some basic questions about the physics of the process. Torgovnikov (1993) in his book on "Dielectric properties of wood and wood based materials" had gathered information for a fuller understanding of the subject. But it also stimulated new research, one the one hand, to refine knowledge about the proven Rf-technology and, on 
the other hand, find proper applications for using microwaves. With the latter, the widespread use of magnetrons for cooking ovens and their stable performance over years proofed to be an incentive. Another stimulant is the energy density that can be attained and permits extremely fast drying rates.

\section{Different Drying Mechanism}

Hf heating has been proven to allow rapid heat transfer throughout dielectric materials. This volumetric heating does not depend on heat transfer through the surface and continues through the boiling point of water and beyond. The wet bulb temperature does not limit the wood temperature. Internal evaporation and an increase in pressure occur in the cells moving liquid water and steam to the evaporating surface, preferentially to the end grain. Especially during the periods of initial heat-up and constant drying rate, moisture flow responds to absolute pressure differences and the permeability of the wood influences the speed of drying. During the falling rate period, when residual liquid water and water vapor are moved, diffusion becomes an additional mechanism. At low moisture contents, when water is tightly adsorbed, dielectric heating decreases with a decreasing loss factor (Perkin 1980; Zhang et al. 1997; Kobayashi et al. 2001; Kawai et al. 2001).

This drying mechanism results, toward the end at lower moisture levels, in rather flat moisture gradients from the interior to the surface. It permits rapid drying because drying stresses are small or non-existent so that checking of the material is minimized or prevented (Resch and Gautsch 2000; Resch and Hansmann 2002). In a study of pine boards heated with microwaves, Liu et al. (2005) showed higher initial vapor pressure in the cores with a fairly uniform temperature distribution. As drying progressed, the core temperature advanced while pressure levels slowly decreased still with a driving force on the inside. When rapidly heating and drying of poplar wood using microwaves, Yang et al. (2005) found the temperature of outer layers initially somewhat higher than of the core, however, observing soon a reversal of this pattern with moisture migration from the inside out.

The explanations above do not necessarily indicate that everything is understood and kiln schedules are optimized. In the last years, basic studies about Hf-heating were conducted by Makoviny (1995); Resnik et al. (1997), Zhou and Avramidis (1999) on the changing loss factor, Perré and Turner (1999) on the numerical simulation of drying with microwaves; Lee and Hayashi (2000a, 2000b) on HfV drying parameters and wood behavior; to name a few. However, the multitude of factors effecting the outcome of HfV kiln runs, the possibilities to effectively combine HfV drying with other heating and drying methods, and the advantages of on-line measurement systems to assess process parameters of heating, evaporation and condensation require further research and development.

An understanding of the mechanism of moisture movement may also be the basis of future control and scheduling of Hf-drying processes. This, in addition to a desire for basic understanding, explains the emphasis placed by a number of researchers on modeling the effects of microwave radiation on the drying process per se (Turner et al. 1998; Perre and Turner 1999; Zhao and Turner 2000; Jia and Afzahl 2005). For continuous HfV-drying of thick lumber, Koumoutsakos et al. 2001a, 2001b, 2002a, 2002b developed a one-dimensional model of flow exclusive of capillary movement.

\section{Technical feasibility}

The available literature indicates the technical feasibility of Hf-drying, specifically:

Refractory woods and timbers of large dimensions can be dried with reduced degrade fresh from the saw;

Drying is possible without stickers providing greater kiln capacity, however, may cause some warp without restraint;

- Well staked timbers can be heated rapidly and, with Rf-power, fairly uniformly throughout a pile; 
When uniform heating is accomplished, drying stresses are small or non existent so that checking does hardly develop;

When drying in vacuum, most of the dried timbers retain their natural light color;

$>$ Drying times required are only a fraction of those needed with conventional methods, however, when drying green from the saw, final moisture equilibrium is not always easily obtained;

Microwaves permit higher energy densities, however, to a more limited depth; too high an energy input may cause steam expansion checks;

Wet areas may be preferentially heated in a re-drying process, thus leveling the moisture content.

\section{Economic considerations}

For economic considerations of a new process and installation of new equipment, the costs of present drying methods need to be known. Besides capital investment, the costs of energy, labor, maintenance, space, pollution, overhead, et cetera should be compared. While increased throughput is an easily determined advantage, the evaluation of improved material quality is much more difficult and may be influenced by bias and market fluctuations. In the lumber and plywood industries, the actual loss in product quality, the downfall during the drying operation, is often poorly understood and sometimes easily accepted when the amount produced has priority.

The economic analyses of producing hardwood furniture stock with RfV drying (Farkas 1993; Smith et al. 1996) and RfV drying of Canadian softwoods (Avramidis and Zwick 1997) provide a positive picture of the Hf-technology in regard to higher value products. Importantly, the latter study pointed out that capital costs are not based on market prices and include development costs.

\section{Changing Generators}

During the last decade, Hf-technology has been improving. Fixed costs of equipment and some of the variable costs have come down, such as the expense for tubes that may not be needed when solidstate technology can be employed. The first Rf-generators were triode oscillators using vacuum tubes that were costly and whose life was a limiting factor. One other draw back was the necessity of readjusting the frequency and the plate voltage from time to time because the dielectric coefficient $\varepsilon^{\prime}$ and the loss tangent $\delta$ of the wood change with moisture loss. Rf-amplifiers normally used in telecommunications appeared more advantageous.

Now, solid-state power amplifiers stand for a new technology. The 50- $\Omega$ systems have a fixed frequency with a crystal oscillator amplifying the required power in several stages (Jones 1996). In the first stage, solid-state devices bring the power up to a few kilowatts and then thermionic valve circuits can boost it further. The use of matchboxes assures balanced impedance. A main advantage is the higher energy conversion efficiency.

The magnetron remains the preferred microwave power source because of stable frequency output at high energy efficiency and low cost. Depending on the size of materials and their dielectric properties, different applicators may be employed such as single mode resonant cavities, multimode ovens or traveling wave applicators. The limited penetration depth of microwaves somewhat restricts choices.

\section{Energy consumption}

The cost of electric energy has certainly been an impediment to adopting Hf-drying technologies. Of course, electricity costs vary greatly with region depending on the availability of hydroelectric, atomic, 
or fossil fuel sources. In forest products industries, the cost of electricity is relatively high in comparison to in house process steam produced from manufacturing residues or biomass.

In the case of HfV-drying of red oak furniture squares reported above, the commercial viability seemed to exist for a number of years. The $100 \mathrm{~mm}$ thick material ranging in initial moisture contents between $82 \%$ and $89 \%$ could be reduced to final moisture contents between $6 \%$ and $8 \%$ in about 66 to 68 hours. The energy consumption ranged between 7.7 and $12 \mathrm{MJ} / \mathrm{kg}$, i.e. 2.14 and $3.33 \mathrm{kWh} / \mathrm{kg}$ of water. The higher consumption appeared to be related to low temperatures in the wintertime. The short drying times and the almost defect free material compensated for the costs of electricity.

In the case of the Canadian studies of RfV-drying of $101 \mathrm{~mm}$ thick softwood, the efficiency appeared to be much higher. From an initially green (fresh from the saw) moisture content to a final of $15 \%$, a use of $1.29 \mathrm{kWh} / \mathrm{kg}$ of water (or $4.64 \mathrm{MJ} / \mathrm{kg}$ ) was reported, providing for a high efficiency of $70 \%$.

Of course, each process situation requires different considerations. To obtain at least an estimate of electric energy consumption for an HfV dryer, one needs to determine the following energies to

heat the wood substance to the drying temperature, $Q_{1}$

heat the water contained, $Q_{2}$

vaporize the water to be removed, $Q_{3}$

break the bonds of adsorbed water to be removed, $Q_{4}$

make up heat losses due to radiation and conduction, $Q_{5}$

run the vacuum pump, $Q_{6}$

run the cooling system, $Q_{7}$.

$Q_{1}$ through $Q_{4}$ can be calculated from theory; the others must be estimated empirically. Here not included is the energy for transporting the charge.

For instance, assuming a $\mathrm{HfV}$ dryer operating at $50^{\circ} \mathrm{C}$ and at $120 \mathrm{mbar}$ with a $\mathrm{Hf}$ conversion efficiency of $60 \%$, large dimension softwood timbers with a density of $375 \mathrm{~kg} / \mathrm{m}^{3}$ (oven dry basis) are to be dried from an initial moisture content of $60 \%$ to a desired final of $18 \%$. An estimate of the energy consumption may be: $5.3 \mathrm{MJ} / \mathrm{kg}$ of water or $1.47 \mathrm{kWh} / \mathrm{kg}$ that is about $232 \mathrm{kWh} / \mathrm{m}^{3}$ of timber.

\section{LITERATURE}

Antti, L. 1992. Microwave drying of hardwood: simultaneous measurements of pressure, temperature, and weight reduction. Forest Prod. J. 42(6): 49-54

Antti, L. 1999. Heating and drying wood using microwave power. PhD-Thesis, Skelleftea.

Abramenko, S.N. 1934. The drying of wood by electric currents of high frequency. Woodworking, USSR 10: 65-68.

Avramidis, S.; Zwick, R.L, 1992. Exploratory radiofrequency/vaccum drying of three B.C. coastal softwoods. Forest Prod. J. 42(7/8): 17-24

Avramidis, S.; Liu, F.; Neilson, J. B. 1994. Radio-frequency/vacuum drying of softwoods: drying of thick western red cedar with constant electrode voltage. Forest Prod. J. 44(1): 41-47

Avramidis, S.; Zwick, R. L.; Neilson, J. B. 1996. Commercial-scale RF/V drying of softwood lumber. Part 1 Basic kiln design considerations. Forest Prod. J. 46(5): 44-51 
Avramidis, S.; Zwick, R.L. 1996. Commercial-scale RF/V drying of software lumber. Part 2. Drying characteristics and lumber quality. Forest Prod. J. 46(6): 27-36

Avramidis, S.; Zwick, R. L. 1997. Commercial-scale RF/V drying of softwood lumber. Part 3. Energy consumption and economics. Forest Prod. J. 47(1): 48-56

Avramidis, S. 1999. Radio frequency vacuum drying of wood. Proceed. Intl. Conference of COST E15 Wood Drying, Edinburgh UK

Birjukov, K. 1950. Kiln seasoning of timber in an R.F. electric field. Goslesbumizdat, LeningradMoscow 102

Czepek, E.; Sporckmann, H. 1968. Hochfrequenztrocknung von Buchenholz in einem süddeutschen Holzwerk. Elektrowärme International 26(12):440-447

Dean, A.R. 1963. Drying timber by R.F.-Heating. Wood 28(2): 65

Djakonov, K. F.; Gorjaev, A. A. 1981. [Wood drying with high frequency current. Forest Management Publishing, 1981 Moskva]

Dunlap, F. 1912. The specific heat of wood. US Forest Service Bull. 110, 28pp

Elustondo, D.; Avramidis, S. 2002. Modeling a timber «dry/sort/re-dry» strategy using combined conventional and dielectric technologies. In Methods for improving drying quality of wood; $4^{\text {th }}$ COST E15 Workshop, Santiago de Compostela, Spain

European Standard, 1999. Round and sawn timber-Method for assessment of casehardening. Draft W.I.91, CEN/TC 175 N 332 E

Farkas, M. S. 1993. RF/V drying of hardwoods - A techno-economic and market study for Niagara Mohawk Power Corp., 31 pgs. New York.

Fujimoto, N.; Yamamoto, Y.; Nagata S. 2005. Hybrid kiln drying with radio-frequency heating for the round timbers of Japanese cedar. $9^{\text {th }}$ Intl. IUFRO Wood Drying Conf. Nanjing, China, 459-462

Fuji Electronic Ind. Co. 2003. High frequency vacuum timber dryer. www.fide.co.jp/products/

Gefahrt, J 1966. Hochfrequenzerwärmung in der Furniertrocknung. Moderne Holzverarbeitung 1(3): 182

Gefahrt, J. 1967. Hochfrequenzwärme in der Holztrocknung. Moderne Holzverarbeitung 2(5): 304

Gillwald, W. 1964. Grundlagen und Perspektiven der Hochfrequenztrocknung. Holzindustrie 17(2): 39

Hamano, Y.; Nishio, S. 1988. Vacuum drying of wood with microwave heating. I. New drying method combining microwave heating and a vacuum. J. Japan Wood Res. Soc. 34(6): 485-490

Hansson, L.; Antti, L. 2003. Design and performance of an industrial microwave drier for on-line drying of wood components. $8^{\text {th }}$ IUFRO Wood Drying Conf., Brasov, Romania: 156-158

Harris, R.A.; Taras, M.A.; Schroeder, J.G. 1984. Sound quality upholstered frame part yields from lumber and green cuttings dried by a radio-frequency/vacuum system and by conventional kilndrying. Forest Prod. J. 34(7/8): 19-21 
Hearmon, R.F.S.; Burcham, J.N. 1954. The dielectric properties of wood. Her Majesty's Stationary Off. Sec. Pep. 8, London

HeatWave Technologies Inc. 2004. www.heatwave.com

Jagfeld, P. 1963. Die Trocknung von Holz im hochfrequenten Wechselfeld. Holz-Zbl. 89(10): 67

James, W.L.; Hamill, D.W. 1965. The dielectric properties of Douglas fir measured at microwave frequencies. Forest Prod. J. 15(2): 51-56

James, W.L. 1975. Dielectric properties of wood and hardboard: variation with temperature, frequency, moisture content, and grain orientation. USDA Forest Prod. Lab. Res. Pap. FPL-245, Madison

Jia, D.; Afzal, M. T. 2005. A comparison in microwave drying of Red Maple (Acer rubrum L.) and White Oak (Quercus alba). $9^{\text {th }}$ Intl. IUFRO Wood Drying Conf. Nanjing, China 197-202

Jones, P.L. 1996. RF Heating, an old technology with a future. Proceedings of Microwave and High Frequency Heating. L 1.1-LI.9.

Kawai, Y.; Kobayashi, Y.; Norimoto, M.; Pulido, O.P. 2001. Water pathways during HF heating of wood. Int. Conf. Development of Wood Science, Ljubljana, Sl.

Kobayashi, Y.; Kawai, Y.; Norimoto, M.; Pulido, O.P. 2001. Industrial application of HF heating during low temperature drying of refractory species of lumber. Intl. Conf. Development of Wood Science, Ljubljana, Sl.

Kollmann, F. 1951. Technologie des Holzes und der Holzwerkstoffe. Bd.2, 2nd ed. Springer, Berlin

Koppelmann, E. 1976. Process and apparatus for seasoning of wood. U.S. Patent 3, 986.268. U.S. Patent Office, Washington DC.

Koumoutsakos, A.; Avramidis, S.; Hatzikiriakos, S. G. 2001'a . Radio frequency vacuum drying of wood. I: Theoretical model. Drying Technol. 19(1): 65-84.

Koumoutsakos, A.; Avramidis, S.; Hatzikiriakos, S. G. 2001b. Radio frequency vacuum drying of wood. II: Experimental model validation. Drying Technol. 19(1): 85-98.

Koumoutsakos, A.; Avramidis, S.; Hatzikiriakos, S. G. 2002. Mass transfer characteristics of Western hemlock and Western red cedar. Holzforschung. 53(2):185-190.

Koumoutsakos, A.; Avramidis, S.; Hatzikiriakos, S. G. 2002. Fundamental phenomena in wood RFV drying with 50-Ohm amplifier technology. Maderas. Ciencia y tecnologia 4(1):15-25.

Lee, H.W. 2005. Microwave drying of large dimension wood I: Korean Red Pine with sectional dimension of 150 by $150 \mathrm{~mm}$. $9^{\text {th }}$ Intl. IUFRO Wood Drying Conf. Nanjing, China 203-206.

Lee, N-H.; Hayashi, K. 2000a. Comparison of shrinkage, checking, and absorbed energy in impact bending of Korean ash squares dried by a radio-frequency/vacuum process and a conventional kiln. Forest Prod. J. 50(2): 69-72

Lee, N-H.; Hayashi, K. 2000b. Effect of end-covering and low pressure steam explosion treatment on drying rate and checking during radio-frequency/vacuum drying of Japanese cedar log cross sections. Forest Prod. J. 50(2): 73-78 
Leiker, M.; Aurich, K. 2003. Sorption behaviour of microwave dried wood. Proceedings 8th IUFRO Wood Drying Conference. Brasov, Romania: 237-240.

Leiker, M.; Adamska, M.A. 2004. Energy efficiency and drying rates during vacuum microwave drying of wood. Holz als Roh- und Werkstoff 62: 203-208.

Leiker, M.; Adamska, M.A.; Giittel, R.; Mollekopf, N. 2004a. Vacuum microwave drying of beech: property profiles and energy efficiency. Proceedings of COST E15 Intl. Conf. Wood Drying, Athens, Greece, 128-137.

Leiker, M.; Adamska, M.A.; Mollekopf, N. 2004b. Microwave drying of single wood boards in multimode cavities. Proceedings of Intl. Workshop and Symposium on Drying, Mumbai, India.

Leiker, M.; Aurich, K.; Adamska M.A. 2005. Accelerated drying of single hardwood boards by combined vacuum-microwave application. $9^{\text {th }}$ Intl. IUFRO Wood Drying Conf. Nanjing, China, 185190

Li, X.; Gao, R.; Kuroda, N.Kobayashi, I. 2005. Studying on RF/V drying characteristics for plantation poplar. 9 $^{\text {th }}$ Intl. IUFRO Wood Drying Conf. Nanjing, China, 191-196

Liu, F.; Avramidis, S.; Zwick, R. 1994. Drying thick Western hemlock in a laboratory radiofrequency/vacuum dryer with constant and variable electrode voltage. Forest Prod. J. 44(6): 71-75

Liu, Z.; Zheng, H.; Zhang, B; Libei, M. 2005. Mechanism of internal moisture migration in wood during microwave drying $9^{\text {th }}$ Intl. IUFRO Wood Drying Conf. Nanjing, China, 220-225

Luth, H.J.;Krupnick S.R. 1945. Method and apparatus for drying lumber. U.S. Patent 2,387.595. U.S. Patent Office, Washington DC.

Makoviny; I. 1995. A contribution to the calculation of the fundamental quantities at high-frequency heating and gluing of wood. Drevarsky Vyskum, Cislo 4: 45-57

Matsumoto, B. 1934. [ ] Japanese Patent 125862

Mc Alister, W.R.; Resch, H. 1971. Drying 1-inch Ponderosa pine lumber with a combination of microwave power and hot air. Forest Prod. J. 21(3): 26-39.

Miller, D.G. 1948. Application of heating to the seasoning of wood. Proc. Forest Prod. Res. Soc. 235

Miller, D.G. 1966. Radio-frequency lumber drying: methods, equipment and costs. Canad. Forest Ind. 86(6): 53

Mokushin, 2001. Kiln dry report. www.mokushin.com.

Murata, J. ; Iso, H., 1949. High frequency methods for wood drying. Mokuzai Kogyo (Wood Industry) 4: $250-256$

Myojin, M.; Hayashi, K;Aavakaillo, T. 2005. Practical development of radio frequency vacuum drying method with hot blow. $9^{\text {th }}$ Intl. IUFRO Wood Drying Conf. Nanjing, China, 435-440.

Perkin, R. M. 1980. The heat and mass transfer characteristics of boiling point drying using radio frequency and microwave electromagnetic fields. Int. J. Heat and Mass Transfer 23: 687 
Perré, P.; Turner, I. W. 1999. The use of numerical simulation as a cognitive tool for studying the microwave drying of softwood in an over-sized waveguide. Wood Science and Technology 33: 445-464

Pound, J. 1973. Radio frequency heating in the timber industry. E. \& F.N. Spon Ltd. London, 191 pp.

Resch, H. 1966. Preliminary technical feasibility study on the use of microwaves for the drying of redwood lumber. Proc. Ann. Meet. - Western Dry Kiln clubs, Redding, California

Resch, H. 1967. Drying Incense cedar pencil slats by microwave power. J. Microwave Power 2, 2: 45-49

Resch, H., 1968. Über die Holztrocknung mit Mikrowellen. Holz als Roh- und Werkstoff, 26(9): 317-324

Resch, H.; Lofdahl, C.A.; Smith, F.J., Erb, C. 1970. Moisture leveling in veneer by microwaves and hot air. Forest Prod. J. 20(10): 50-58

Resch, H.; Hansmann, C.; Pokorny, M. 2000. The color of wood from white oak. Holzforschung u. Holzverwertung, 52(1): 13-15

Resch, H.; Gautsch, E. 2000. Vakuumtrocknung von Schnittholz im dielektrischen Wechselfeld. Holzforschung u. Holzverwertung, 52(5): 105-108

Resch, H.; Hansmann, C. 2002. Tests to dry thick Eucalyptus boards in vacuum using high frequency heating. Holzforschung $u$. Holzverwertung, 54(3): 59-61

Resch, H. 2003. High-frequency heating combined with vacuum drying of wood. $8^{\text {th }}$ Intl. IUFRO Wood Drying Conf., Brasov, Romania, 127-132.

Resnik, J.; Sernek, M.; Kamke, F., 1997. High-frequency heating of wood with moisture content gradient. Wood and Fiber Science, 29(3): 264-271

Russian Academy of Science, (undated) Vacuum dielectric apparatus for seasoning wood, Scientific Productional Centre of Informational and Industrial Technologies Moscow

Smith, W.B.;Canham; H.O.; Harris, J.; Neuhauser, E.F.; Smith, A. 1996. Economic analysis of producing red oak dimension squares with a radio-frequency vacuum dry kiln. Forest Prod. J. 46(3): 30-34

Stephen, J.L.; Holmquest, H. J. 1936a. Drying lumber with high-frequency electric fields. Wood Products 41(10): 10-12.

Stephen, J.L.; Holmquest, H. J. 1936b. Drying lumber with high-frequency electric fields. Wood Products 41(11): 15-19.

Tiemann, H.D. 1944. Wood Technology. $2^{\text {nd }}$ ed. New York and Chicago

Tinga W.; Nelson S.O. 1973. Dielectric properties of materials for microwave processing - tabulated. J. Microwave Power 8(1): 23

Torgovnikov, G.I. 1993. Dielectric properties of wood and wood based materials. Springer Verlag Berlin, 194 pp. 
Trofatter, G.; Harris, R.A.; Schroeder, J.; Taras, M.A. 1986: Comparison of moisture content variation in red oak lumber dried by a radio-frequency/vacuum process and a conventional kiln. Forest Prod. J. 36(5): 25-28.

Turner, I.W.; Puigalli, J.R.; Jomaa, W. 1998. Numerical investigation of combined microwave and convective drying of a hygroscopic porous material. Trans. IchemE.76 (A): 193-209

Voigt, H.; Krischer, O.; Schauss, H.1940. Sondernverfahren der Holztrocknung. Holz Roh- $u$. Werkstoff, 3(11): 364.

Von Hippel, A.R. 1959. Dielectrics and waves. John Wiley, New York

Wang, X. 2005. A study on drying stress relaxation of wood subjected to microwave radiation. $9^{\text {th }}$ Intl. IUFRO Wood Drying Conf. Nanjing, China, 214-219

Wilson, J.B. 1989. Radio-frequency drying of wood veneer - commercial use. J. Microwave Power and Electromagnetic Energy 24(2): 67-73.

Yang; W.; Chen, M.; Zheng, L. 2005. Study on the varying law of Moisture Content and Temperature of wood during microwave drying. $9^{\text {th }}$ Intl. IUFRO Wood Drying Conf. Nanjing, China, 207-213

Yasujima, 2001. High Elec Dryer EX. www.jeims.co.jp

Zhang, L.; Avramidis, S.; Hatzikiriakos, S.G. 1997. Moisture flow characteristics during radio frequency vacuum drying of thick lumber. Wood Science and Technology 31(4): 265-277

Zhao, H.; Turner, I.W. 2000. The use of a coupled computational model for studying the microwave heating of wood. Appl. Math. Modeling 24: 183-197

Zhou, B.; Avramidis, S. 1999. On the loss factor of wood during radio frequency heating. Wood Science and Technology 33:299-31

Zhu, Z.X.; Xiang, M.D.; Jiang, R.S.; Liu, J.; Bai, B.; Chu, Z.Y.; Zheng, J.D.; Ma, L.S.; Yu, J.L.; Shan, Y.M. 1985. Study on the drying of lumber with microwave energy. J. NE Forestry University, China, 13, 4: 1-7

Zielonka, P.; Dolowy, K. 1998. Microwave drying of spruce: moisture content, temperature and heat energy distribution. Forest Prod. J. 48(6): 77-80 